\section{Regards sur l'économie allemande}

Bulletin économique du CIRAC

$81 \mid 2007$

Varia

\title{
Recherche : dépenses des Fraunhofer \& Co. en hausse
}

\section{Isabelle Bourgeois}

\section{(2) OpenEdition}

1 Journals

Édition électronique

URL : http://journals.openedition.org/rea/676

DOI : 10.4000/rea.676

ISBN : 978-2-8218-0858-4

ISSN : 1965-0787

\section{Éditeur}

CIRAC

Édition imprimée

Date de publication : 1 mai 2007

Pagination : 38

ISSN : 1156-8992

Référence électronique

Isabelle Bourgeois, «Recherche: dépenses des Fraunhofer \& Co. en hausse », Regards sur l'économie allemande [En ligne], 81 | mai 2007, document 3, mis en ligne le 01 mai 2009, consulté le 15 septembre 2020. URL : http://journals.openedition.org/rea/676

Ce document a été généré automatiquement le 15 septembre 2020

(c) CIRAC 


\title{
Recherche : dépenses des Fraunhofer \& Co. en hausse
}

\author{
Isabelle Bourgeois
}

1 Les établissements extra-universitaires de recherche ont vu leur budget en hausse en 2005, à en croire les données publiées par Destatis le 30 mars. Leurs dépenses de R\&D se sont élevées à 7,9 milliards $€$, soit une progression de $4,7 \%$ en un an. Elle est due essentiellement à l'investissement, en augmentation de $13,1 \%$.

2 Ces établissements, de statut privé pour la plupart et subventionnés conjointement par le Bund et les Länder, comptent dans leurs rangs les centres Helmholtz, les Instituts Fraunhofer et Max-Planck, de même que les membres de la Société Leibniz. Ils constituent l'un des trois piliers du système allemand de R\&D, les deux autres étant les universités et les entreprises. La répartition traditionnelle de l'effort de R\&D n'a pas varié : en 2005 aussi, universités et établissements extra-universitaires de recherche contribuaient pour un tiers à l'effort de R\&D allemand ( $2,5 \%$ du PIB), les entreprises apportant les deux tiers restants.

3 Les dépenses des établissements privés de recherche se sont élevées à 5,8 milliards $€$, soit près des trois quarts du total du dispositif extra-universitaire. Les centres Helmholtz se taillent la part du lion avec 2,5 milliards $€$, suivis des instituts Fraunhofer $(1,3$ milliard $€)$, Max Planck $(1,2$ milliard $€)$ et des centres de la société Leibniz $(0,8$ milliard $€$ ). Les établissements publics (dont les centres de recherche des musées et bibliothèques) n'ont dépensé, quant à eux, que 2 milliards $€$. Il est vrai que les établissements privés travaillent en étroit partenariat avec les entreprises et que son apport est primordial pour l'innovation incrémentale qui fait la compétitivité de l'économie allemande. La hausse des dépenses de ces centres extra-universitaires est donc de bon augure : l'Allemagne progresse, lentement certes, mais sûrement, dans la réalisation de l'objectif des $3 \%$ de R\&D à l'horizon 2010 fixé dans le cadre de la Stratégie de Lisbonne. 
INDEX

Mots-clés : investissement, R\&D, recherche 